\title{
Isolation and Characterization of Hydrocarbon-Degrading Yeast Strains from Petroleum Contaminated Industrial Wastewater
}

\author{
Boutheina Gargouri, Najla Mhiri, Fatma Karray, Fathi Aloui, and Sami Sayadi \\ Laboratoire des Bioprocédés Environnementaux, Centre de Biotechnologie de Sfax, Université of Sfax, BP 1177, 3018 Sfax, Tunisia \\ Correspondence should be addressed to Boutheina Gargouri; boutheina_fss@yahoo.fr
}

Received 13 November 2014; Revised 28 March 2015; Accepted 5 April 2015

Academic Editor: J. P. A. Hettiaratchi

Copyright (c) 2015 Boutheina Gargouri et al. This is an open access article distributed under the Creative Commons Attribution License, which permits unrestricted use, distribution, and reproduction in any medium, provided the original work is properly cited.

\begin{abstract}
Two yeast strains are enriched and isolated from industrial refinery wastewater. These strains were observed for their ability to utilize several classes of petroleum hydrocarbons substrates, such as $n$-alkanes and aromatic hydrocarbons as a sole carbon source. Phylogenetic analysis based on the D1/D2 variable domain and the ITS-region sequences indicated that strains HC1 and HC4 were members of the genera Candida and Trichosporon, respectively. The mechanism of hydrocarbon uptaking by yeast, Candida, and Trichosporon has been studied by means of the kinetic analysis of hydrocarbons-degrading yeasts growth and substrate assimilation. Biodegradation capacity and biomass quantity were daily measured during twelve days by gravimetric analysis and gas chromatography coupled with mass spectrometry techniques. Removal of $n$-alkanes indicated a strong ability of hydrocarbon biodegradation by the isolated yeast strains. These two strains grew on long-chain $n$-alkane, diesel oil, and crude oil but failed to grow on short-chain $n$-alkane and aromatic hydrocarbons. Growth measurement attributes of the isolates, using $n$-hexadecane, diesel oil, and crude oil as substrates, showed that strain $\mathrm{HCl}$ had better degradation for hydrocarbon substrates than strain $\mathrm{HC}$. In conclusion, these yeast strains can be useful for the bioremediation process and decreasing petroleum pollution in wastewater contaminated with petroleum hydrocarbons.
\end{abstract}

\section{Introduction}

Soil and water contamination are frequently caused by oil and oil-related compounds. Strategies for controlling environmental contamination by petroleum and its derivatives have been the subject of various studies over the past three decades. When a spillage occurs, the first action is to remove the oily phase by mechanical or physicochemical means through the application of surfactants in order to disperse the oil layer. Although a variety of physicochemical techniques are available for the clean-up of water surface, some interest in the use of microbial biodegradative activity is growing [1]. Biodegradation is an alternative that has been used to eliminate or minimise the effects of pollutants by using microorganisms which have biodegradation potential [2]. In these environments, organic pollutants frequently occur when mixed with other synthetic or natural organic compounds. Microorganisms, potentiality pointed out in the literature as degradation agents of several compounds, indicate that biodegradation is one of the most promising alternative of biological treatments to reduce the environmental impact caused by oil spills. Moreover, it is known that the main microorganisms consuming petroleum hydrocarbons are bacteria, yeasts, and fungi [3].

Therefore, it is necessary to understand how the biodegradation of the polluting compounds is affected by the presence of alternate substrates. It is also necessary to study the microbial degradation of crude oil as an environmentally friendly way of cleaning up oil-polluted areas.

The first step in such studies is to isolate and identify the microorganisms from contaminated soil and water which are capable of crude oil degradation. Among many studies conducted on microbial biodegradation of oil-related contaminants, more than $80 \%$ are devoted to bacterial biodegradation. Bacteria are the most studied microorganisms and their participation during hydrocarbon mineralization in 
water has been studied by many authors [4]. However, not only are bacteria capable of hydrocarbon biodegradation but also yeasts isolated from hydrocarbon contaminated sites display the ability to use oil-related compounds $[5,6]$. As a matter of fact, a wide variety of yeasts and filamentous fungi are capable of utilizing hydrocarbons. Yeasts capable of degrading hydrocarbons include genera of Yarrowia lipolytica, Candida tropicalis, Candida albicans, and Debaryomyces hansenii. The alkane-utilizing yeast Y. lipolytica degrades very efficiently hydrophobic substrates (HS) such as triglycerides (fats, oils), alkanes, and fatty acids. It has been observed that $Y$. lipolytica is the predominant yeast form during alkane degradation and emulsifier production [7].

The study of hydrocarbon biodegradation by native microorganisms is of extreme ecological importance. The actual contribution of yeasts in the biodegradation of hydrocarbons in the environment may be more important than that previously expected, considering the metabolic diversity demonstrated for yeasts [8]. However, bioavailability of hydrophobic organic compounds to microorganisms is generally a limiting step during the biodegradation process [9]. Hydrophobic interactions play an important role in the adherence of microorganisms to a wide variety of surfaces [10]. In particular, the hydrophobic nature of the bacterial surface has been cited as a key factor in cells growth on water-insoluble hydrophobic substrates such as hydrocarbon $[11,12]$. To enter cells, HS must interact with the cell surface. Two hypotheses have been formulated to explain this step of poorly water-miscible substrates transport into microorganisms: (i) the compounds can be solubilised (or pseudosolubilised) in the presence of surface-active compounds (surfactant-mediated transport) or (ii) they can adhere directly to the cell wall (direct interfacial transport) [13]. The aforementioned yeast species can produce surfactants during growth on HS. A correlation has been observed between cells and HS adhesion induction and the increase in apolar properties of the cell surface [13]. Aerobic degradation of alkanes can be carried out by two major types of enzymes: the alkane monooxygenase (also known as alkane hydroxylase, or AlkB) and certain cytochrome P450 systems.

In a screening program carried out in our laboratory, we isolated yeast strains from petroleum contaminated wastewater effluents that are able to utilize hydrocarbons. The use of naturally occurring yeasts represents a potentially promising means of destroying polluting chemicals in wastewater treatment systems and soil. Therefore, the objective of the present work was to isolate, identify, and characterize $n$-alkane using yeasts capable of degrading petroleum hydrocarbons in order to employ yeasts strains in the future as a biodegrader of polluted environment. The hydrocarbon degradation activity and cell hydrophobicity were also investigated in relation to $n$-alkane utilization.

\section{Material and Methods}

2.1. Isolation and Characterization of Yeast Isolates. The hydrocarbons-degrading microbial consortium was enriched from petrochemical industrial wastewater using a continuously stirred tank-reactor CSTR [14]. Two of the best-growing yeast strains were isolated from the hydrocarbons-degrading microbial consortium. The yeast strains were isolated by using a selective enrichment culture and a single-colony isolation technique. The selected yeasts were identified in the present study by routine morphological, microbiological, and biochemical methods following directions of the latest edition of Bergey's Manual [15].

2.2. Culture Conditions. Yeast isolates were cultivated in $250 \mathrm{ml}$ Erlenmeyer flasks containing $50 \mathrm{ml}$ of mineral medium (MM). The $\mathrm{pH}$ was measured using the Cyberscan $500 \mathrm{pH}$ meter. The $\mathrm{pH}$ was adjusted by using $1 \mathrm{~N}$ standard $\mathrm{NaOH}$ and $1 \mathrm{~N}$ standard $\mathrm{HCl}$ (Merck, Germany). The mineral medium used contained per litre $3.4 \mathrm{~g} \mathrm{~K}_{2} \mathrm{HPO}_{4}, 4.3 \mathrm{~g}$ $\mathrm{KH}_{2} \mathrm{PO}_{4}, 0.3 \mathrm{~g} \mathrm{MgCl}_{2} \cdot 2 \mathrm{H}_{2} \mathrm{O}$, and $1 \mathrm{~g}\left(\mathrm{NH}_{4}\right)_{2} \mathrm{SO}_{4}$, which was supplemented with $1 \mathrm{ml}$ of a trace element solution [16]. The media used for the yeast growth were sterilized by autoclaving at $121^{\circ} \mathrm{C}$ for 20 minutes. Petroleum compounds and derivatives were added as carbon source to the sterilized MM at the desired concentrations. A liquid culture was started by adding a loop full of cells from a standard agar plate into a $250 \mathrm{ml}$ Erlenmeyer flask containing a $50 \mathrm{ml}$ medium. Flasks were inoculated with $1 \mathrm{ml}$ cultures pregrown. Then, isolates were incubated at $30^{\circ} \mathrm{C}$ under agitation $(180 \mathrm{rpm})$ for $10-15$ days (depending on the strain). Samples were taken at intervals from shake flasks. The isolated yeast was also grown on Potato Dextrose Agar (PDA) in order to observe larger colonies for better study. Growth was assessed by measuring the optical density (OD) at $600 \mathrm{~nm}$. Three independent experiments were carried out for each yeast strain.

\subsection{Biomass Growth during the Biodegradation Process.} Biomass concentration was estimated from the absorbance of appropriately diluted culture medium at $600 \mathrm{~nm}$ (Ultrospec 3300 pro UV/Visible) according to the predetermined correlation between optical density and dry weight of biomass. During the biodegradation assays, the number of viable yeasts was measured by counting of heterotrophic microbes in Petri dishes, expressing the result as colony-forming units (CFU) per $\mathrm{ml}$. With a sterile pipette, $1 \mathrm{ml}$ of sample was taken from the culture and a series of $1: 10$ dilutions made in $\mathrm{NaCl}$ solution at $0.9 \%$. Each dilution was analysed in duplicate: $1 \mathrm{ml}$ of sample to be analysed was placed on Petri dishes. Then, $20 \mathrm{ml}$ of previously sterilized culture medium was poured onto the Petri dishes, tempered at $60^{\circ} \mathrm{C}$, and gently stirred to complete the homogenization. The mixture was cooled until complete solidification and then incubated at $30^{\circ} \mathrm{C}$ for $72 \mathrm{~h}$. The total number of microorganisms was determined by multiplying the number of CFU by the corresponding dilution factor. The count was made in an automatic colony counter (Countermat, Flash IUL Instruments). All experiments were performed in triplicate with appropriate controls.

2.4. Cell Surface Hydrophobicity Test. Cell surface hydrophobicity was measured by microbial adherence to hexadecane according to the method of Rosenberg et al. [17]. Yeast strains 
were grown in $50 \mathrm{ml}$ basal medium containing hexadecane $(1.5 \%)$ or glucose $(20 \mathrm{mM})$ as sole carbon source. Yeast cells were washed twice and resuspended in PUM buffer, pH $7.1\left(22.2 \mathrm{~g} \mathrm{~K}_{2} \mathrm{HPO}_{4} \cdot 3 \mathrm{H}_{2} \mathrm{O}, 7.26 \mathrm{~g} \mathrm{KH}_{2} \mathrm{PO}_{4}, 1.8 \mathrm{~g}\right.$ urea, $0.2 \mathrm{~g} \mathrm{MgSO}_{4} \cdot 7 \mathrm{H}_{2} \mathrm{O}$, and distilled water of $1000 \mathrm{ml}$ ), to an initial absorbance at $550 \mathrm{~nm}$ of $0.5-0.6$. The cell suspension $(1.2 \mathrm{ml})$ with hexadecane $(0.2 \mathrm{ml})$ was vortexed in a test tube vigorously for $2 \mathrm{~min}$ and left at room temperature for $1 \mathrm{~h}$. The optical density of the bottom aqueous phase was then measured at $550 \mathrm{~nm}$. Hydrophobicity was expressed as the percentage of adherence to the hydrocarbon which was calculated using the following:

$$
\begin{aligned}
& \text { \% Hydrophobicity } \\
& \qquad=100 \times\left(1-\frac{\text { OD of the aqueous phase }}{\text { OD of the initial cell suspension }}\right) .
\end{aligned}
$$

Hydrophobicity of the yeasts grown on glucose was the reference of hydrophobicity.

\subsection{Tests of Hydrocarbon Tolerance and Biodegradation} Studies. In order to determine the degradation of $n$ alkanes present in the hydrocarbon-rich wastewater by the selected yeast isolate, the total petroleum hydrocarbon (TPH) was determined by the gravimetric weight loss technique [18]. The analyses of hydrocarbons were carried out after dichloromethane extraction. The aqueous phase sample was removed and put in a sealed flask for subsequent analysis. Then, it was concentrated to approximately $3 \mathrm{ml}$ using a rotary evaporator under reduced pressure in a water bath. Afterwards, it was dissolved in equal volume of dichloromethane and further cleaned through a column filled with florisil (SUPELCLEAN LC-FLORISIL, USA) and then analyzed by gas chromatography, mass spectrometry apparatus. After the evaporation of the solvent, the amount of residual TPH was determined by gravimetric methods after dichloromethane evaporation by simple distillation at $60^{\circ} \mathrm{C}$ [18]. Hydrocarbon content was determined using an extraction of hydrocarbon according to the standard method for oil gravimetric determination. The degree of biodegradation was calculated as $[1-(X o-X 1) / X o] 100 \%$ [\%], where $X o$ is initial amount of hydrocarbon and $X 1$ is amount of hydrocarbon after biodegradation.

The ability of the selected strains to utilize hydrocarbons as the sole carbon source was tested by growing yeasts strains in MM with different hydrocarbons in separate flasks. The biodegradation assay was carried out over 12 days in six $250 \mathrm{ml}$ Erlenmeyer flasks (corresponding to 0, 4, 6, 9, and 12 days of experiment, resp.), with each flask containing $50 \mathrm{ml}$ of the mineral medium and $10 \%$ of acclimated inoculum under aseptic conditions. For the induction and hydrocarbon degradation studies using nonproliferating cells, strains $\mathrm{HCl}$ and $\mathrm{HC} 4$ were grown in Erlenmeyer flasks containing $50 \mathrm{ml} \mathrm{MM}$ with $1 \%$ hydrocarbon compounds as the sole carbon and energy source and were incubated in a rotary shaker $(180 \mathrm{rpm})$ at $30^{\circ} \mathrm{C}$. The cells were washed twice with sterile $50 \mathrm{mM}$ potassium phosphate buffer, $\mathrm{pH}$ 7.6. Growth on individual substrate was removed periodically to assess the concentration of following changes in optical density at $600 \mathrm{~nm}$ of washed cells against biotic (without a substrate) and sterile (without bacteria) controls and tested for its bioremediation capacity in situ mesocosm to degrade multiple substrates after 12-day incubation period.

2.6. Hydrocarbon Analysis. The evaluation of the hydrocarbons biodegradation of the contaminated wastewater effluent by yeast strains was carried out during the process of 12 days using gas chromatography with mass spectrometry GC/MS. After 12 days of incubation, the undegraded alkane hydrocarbon residue was extracted twice with equal volumes of dichloromethane and the aromatic residue with toluene. One microlitre of the alkane fraction (dissolved in dichloromethane) was analyzed by gas chromatography analysis GC/MS (Shimadzu, Model 5975B inert MSD) using a HP5MS chromatographic column (5\% phenyl Methyl Siloxane) of size $30 \mathrm{~m} \times 0.25 \mathrm{~mm} \times 0.25 \mu \mathrm{m}$. The temperature was programmed to vary linearly from $70^{\circ} \mathrm{C}$ to $230^{\circ} \mathrm{C}$ at the rate of $20^{\circ} \mathrm{C} \mathrm{min}$ min $^{-1}$ then from $230^{\circ} \mathrm{C}$ to $300^{\circ} \mathrm{C}$ at $40^{\circ} \mathrm{C} \mathrm{min}^{-1}$ and $10 \mathrm{~min}$ at $300^{\circ} \mathrm{C}$. Samples of $1.0 \mu \mathrm{l}$ were injected into the GC/MS, operating in the splitless mode with an injector temperature of $250^{\circ} \mathrm{C}$, and Helium was the carrier gas.

Similarly, the aromatic fraction was dissolved in toluene and $1 \mathrm{ml}$ was analyzed by GC/MS using a 30-m long HP5.MS ( $0.25 \mathrm{~mm}$ film thickness) column. During analysis, the injector and detector of GC/MS were maintained at $300^{\circ} \mathrm{C}$ and the oven temperature was programmed to rise from $150^{\circ} \mathrm{C}$ to $300^{\circ} \mathrm{C}$ with an increase of $5^{\circ} \mathrm{C}$ per minute and then held at $300^{\circ} \mathrm{C}$ for $5 \mathrm{~min}$.

The highest resolution chromatographic peaks were scanned to find their corresponding mass fragmentation profile. Compounds were characterized based on similarities between their mass spectrum and those presented by Wiley Compounds Library. Control peak-areas were used as a point of reference for the remaining compounds (100\%) in the untreated system. Sample peak-areas were reported as a percentage of control peak-areas. Individual compounds present in the alkane and aromatic fractions were determined by matching the retention times with authentic standards (the n-alkanes: C8, C10, C11, C12, C13, C14, C17, C18, C19, C20, C21, C22, C23, C24, C25, C28, and C30 and the aromatic hydrocarbon standards fluoranthene, pyrene, phenanthrene, and anthracene were obtained from Sigma-Aldrich, USA).

\subsection{Identification and Phylogenetic Affiliation of the} Yeast Strains. Genomic DNA of the strains $\mathrm{HCl}$ and HC4 was isolated using a protocol described by MasneufPomarède et al. (2007) [19]. The primers ITS1 $\left(5^{\prime}-\right.$ TCCGTAGGTGAACCTGCGG-3') and ITS4 (5'-TCCTCCGCTTATTGATATGC- ${ }^{\prime}$ ) described by White et al. (1990) [20] were used to amplify the 5.8S ITS region of strain HC4. The D1/D2 domain of $26 \mathrm{~S}$ rDNA gene of strain $\mathrm{HCl}$ was amplified under the same conditions with primers NL1 $\left(5^{\prime}\right.$-GCATATCAATAAGCGGAGGAAAAG-3 $\left.3^{\prime}\right)$ and NL4 (5'-GGTCCGTGTTTCAAGACGG-3 ${ }^{\prime}$ ) [21]. The PCR reaction was performed on a Thermocycler GeneAmp PCR System 9700 (Applied Biosystems) in a $50 \mu \mathrm{l}$ reaction mixture 
containing 5x GoTaq reaction buffer (Promega), $0.25 \mathrm{mM}$ each dNTP, $0.2 \mu \mathrm{M}$ each primer, $50 \mathrm{ng}$ DNA template, and 2.5 U GoTaq DNA polymerase (Promega). The PCR program was as follows: denatured by heating for $2 \mathrm{~min}$ at $94^{\circ} \mathrm{C}$ and subjected to 30 cycles for $30 \mathrm{~s}$ at $94^{\circ} \mathrm{C}, 45 \mathrm{~s}$ at $58^{\circ} \mathrm{C}$, and $1 \mathrm{~min}$ $45 \mathrm{~s}$ at $72^{\circ} \mathrm{C}$, this was followed by a final elongation step for $10 \mathrm{~min}$ at $72^{\circ} \mathrm{C}$. PCR products were purified with illustra GFX PCR DNA and Gel Band Purification kit (Amersham Biosciences, GE Healthcare) according to the manufacturer's protocol. DNA sequencing of PCR products was performed using a BigDye Terminator v3.1 Cycle Sequencing Kit on the ABI PRISM 3100-Avant Genetic Analyser (Applied Biosystems). Target sequences were analyzed using BLAST online (https://blast.ncbi.nlm.nih.gov/) [22]. The related sequences were collected and aligned using the MUSCLE software $[23,24]$. A phylogenetic tree was constructed using the neighbor-joining method in MEGA version 4.1. Yeast species were identified based on the phylogenetic analysis results [25]. The topology of the distance tree was tested by resampling data with 1000 bootstraps to provide confidence estimates. Nucleotide sequences obtained in this work were deposited in the NCBI GenBank data library.

\section{Results and Discussion}

3.1. Isolation and Screening of Hydrocarbons-Degrading Microorganisms. To isolate different hydrocarbon-degrading yeasts, enrichment culture methods were used according to protocol described in Material and Methods. The enrichment procedure for obtaining contaminated wastewater hydrocarbon-degrading microbes was performed in multiple cycles to ensure that the microbes which were obtained at the end of the enrichment cycle were capable of utilizing the petroleum compounds rather than just tolerating it. Five yeast strains were isolated from enrichment cultures that were established at $30^{\circ} \mathrm{C}$ for 2 weeks. Two of the isolated strains that showed higher growth rate on crude oil were selected from the five isolates for further study. These isolates showed a varying degradation profile for the total petroleum hydrocarbon $[\mathrm{TPH}]$ of the petroleum contaminated wastewater. It varied from $29.5 \%$ to $95 \%$ (Figure 1). In our present work, we report that yeasts Candida tropicalis and Trichosporon asahii could efficiently degrade total petroleum hydrocarbon removal about $97 \%$ and $95 \%$, respectively, over a period of 20 days. According to many authors, bacteria have been described as being more efficient hydrocarbon degraders than yeast or at least that bacteria are more commonly used as a test microorganism [26-28]. Many other investigators have reported the involvement of bacteria and yeast in crude oil biodegradation [12, 29]. On the contrary, there is scanty information that yeasts are better hydrocarbon degraders than bacteria $[11,30]$. For that reason, growth ability of two selected strains ( $\mathrm{HCl}$ and $\mathrm{HC} 4)$ was tested in an enrichment liquid medium.

3.2. Phylogenetic Analyses of the Yeast-Degrading Hydrocarbon. To analyse the phylogenetic position of the yeast

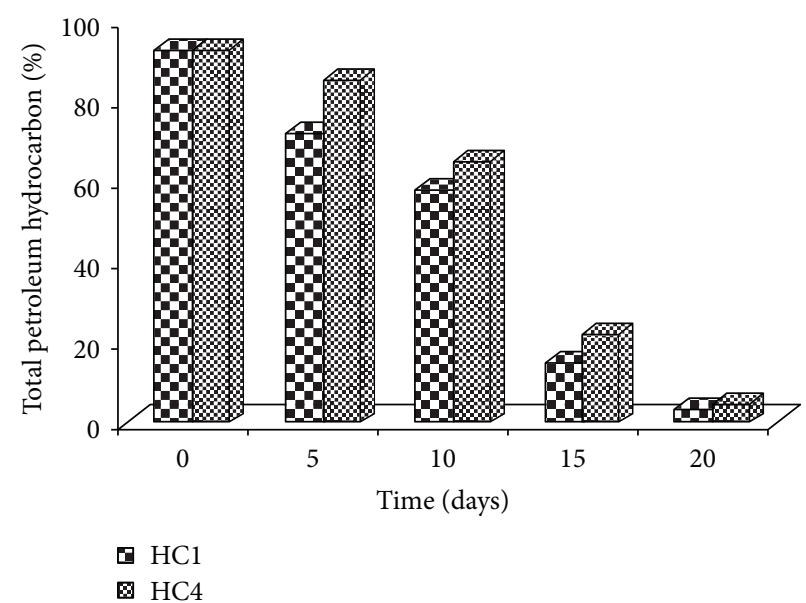

FiguRE 1: Biodegradation efficiency of yeast strains.

isolates, the 26S rRNA gene of isolate $\mathrm{HCl}$ and the 5.8SITS noncoding regions of the rDNA of the isolate $\mathrm{HC} 4$ were amplified, sequenced, and compared with those available in the GenBank nucleotides sequences database. Percentage similarity values were obtained after pairwise alignment of the sequences of the $16 \mathrm{~S}$ rDNA of the yeast strains and EMBL database sequences. The sequences giving the highest scores were retried to construct the phylogenetics dendograms. Sequence comparison demonstrated the affiliation of the strain $\mathrm{HCl}$ to the genus Candida. The phylogenetic analysis based on the D1/D2 sequences showed that strain $\mathrm{HC} 1$ belongs to ascomycetous yeasts and indicated that strain $\mathrm{HCl}$ is closely associated with the speciesof Candida tropicalis in Figure 2(a). The determined sequences displayed similarities of $99.4 \%, 99 \%, 98.8 \%$, and $99 \%$ to Candida sojae, Candida tetrigidarum, Candida maltosa, and Candida neerlandica, respectively $[31,32]$.

Identification of the yeast strain $\mathrm{HC} 4$ was performed by amplifying the 5.8-ITS rRNA. Compared to the 5.8-ITS rDNA sequence analysis, it was observed that the strain $\mathrm{HC} 4$ has identical sequence to Trichosporon asahii CBS $2479^{\mathrm{T}}$. Basidiomycetous yeast HC4 strain was clustered closely with Trichosporon asahii and showed also more than $99 \%$ similarity between the 16s rRNA gene sequences with the Trichosporon astreoides and Trichosporon coremiiforme. Basidiomycetous yeast HC4 also shared similarity of about $99.7 \%$, 99\%, and 99.8\% identities with Trichosporon faecale, Trichosporon japonicum, and Trichosporon aquatile, respectively [33]. Phylogenetic relationships of the sequence of 5.8S ITS region of the yeast strain $\mathrm{HC} 4$ are shown in Figure 2(b) and placed this isolate in the Ovoides clade of the genus Trichosporon. The nucleotide sequences for the two yeast strains ( $\mathrm{HCl}$ and $\mathrm{HC} 4$ ) determined in this study have been deposited in the GenBank under the accession numbers JN088216 and JN088217, respectively. Candida tropicalis and Trichosporon asahii are a well-known species of microorganisms to degrade hydrocarbons and have been used widely for petroleum remediation $[34,35]$. 


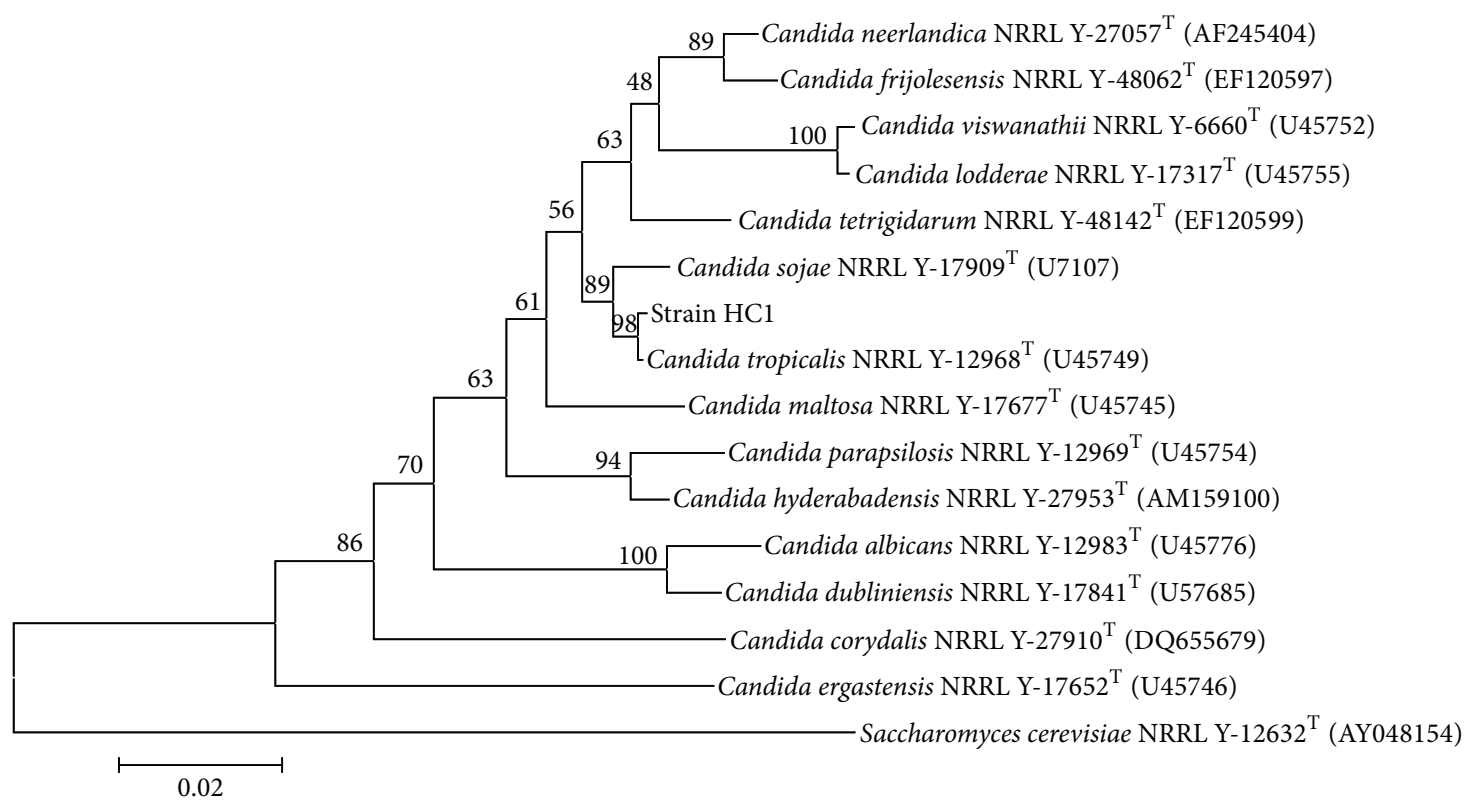

(a)

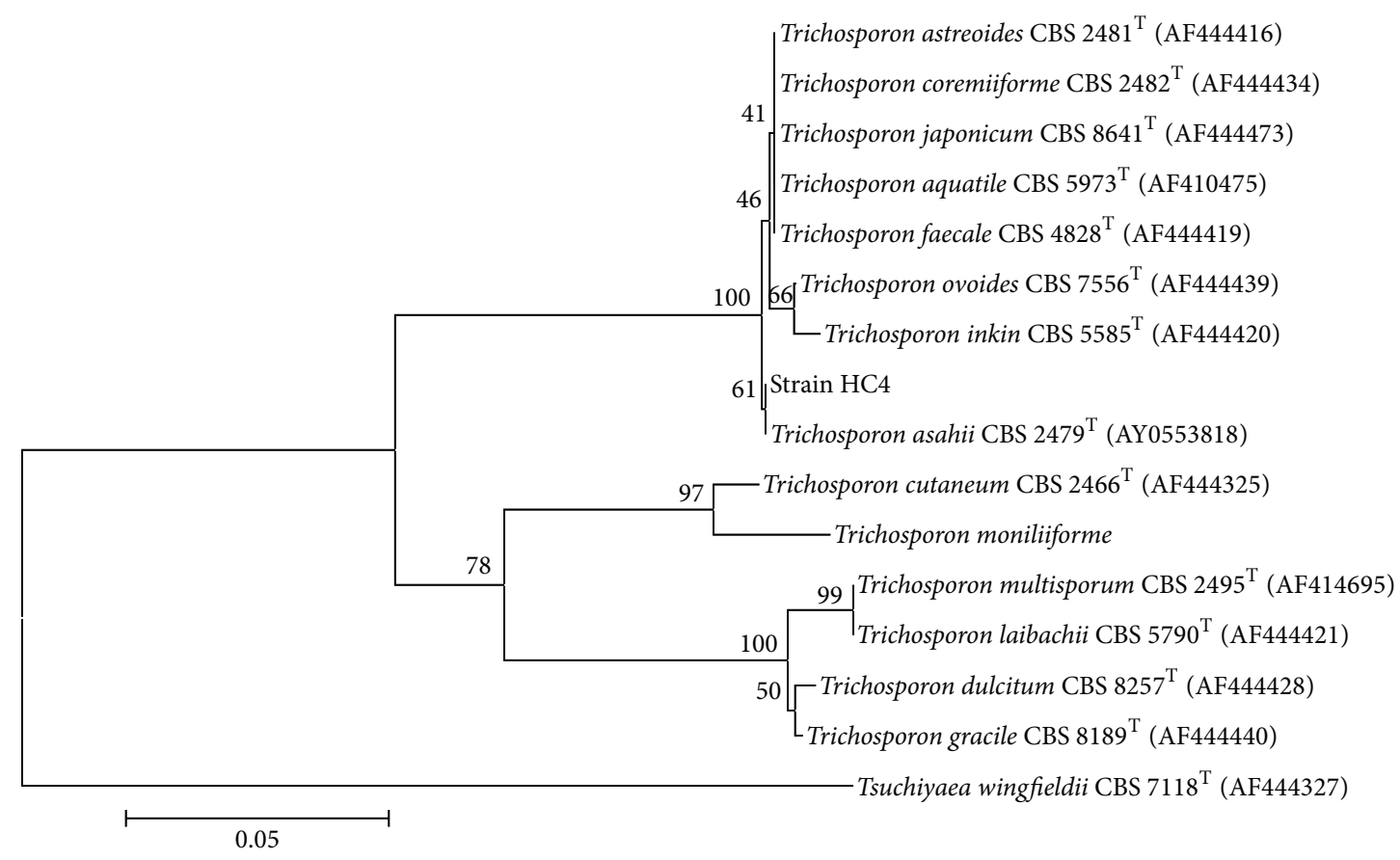

(b)

Figure 2: Phylogenetic dendogram data showing the taxonomic location of strains HC1 and HC4. (a) Neighbour-joining phylogenetic dendogram based on sequences of the D1/D2 domain of the 26S rRNA gene of HC1 and related taxa. Bootstrap values are given at the nodes. Scale bar represents the substitution percentage. Saccharomyces cerevisiae NRRL Y-12632 ${ }^{\mathrm{T}}$ was used as outgroup. GenBank accession numbers follow species name in parenthesis. (b) Phylogenetic dendogram obtained by neighbour-joining analysis of the 5.8S-ITS sequence of HC4 and related taxa. Bootstrap values, determined from 100 replicates, are shown at branch nodes. Scale bar represents the substitution percentage. The outgroup we used was Tsuchiyaea wingfieldii CBS $7118^{\mathrm{T}}$. GenBank accession numbers follow species name in parenthesis.

3.3. Cell Surface Hydrophobicity. Results for cell surface hydrophobicity when the strains were grown on hexadecane and glucose are shown in Figure 3. As it can be seen, cell hydrophobicity of tested strains remained unchanged during growth on glucose. Cell hydrophobicity reached approximately 78 and $85.4 \%$ with Trichosporon and Candida strains, respectively. During our studies, and for both yeast strains, we noticed that the maximal increase in hydrophobicity is 


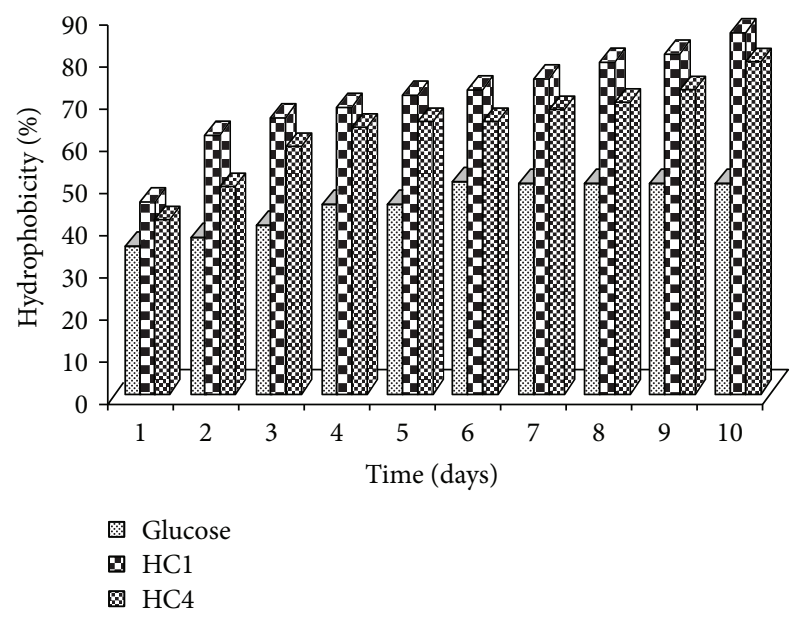

FIGURE 3: Hydrophobicity of yeast strains isolates during growth in mineral medium with $1.5 \%$ hexadecane or glucose as a sole carbon source. $\square$ after growth on glucose; $\boldsymbol{\square}$, after growth on hexadecane. Values are the mean of three separate experiments \pm s.d.

correlated with the maximum biodegradation of hexadecane (or TPH). A direct relationship was found between both cell hydrophobicity of yeast strains and petroleum hydrocarbon biodegradation (Figures 1-3). Based on data obtained from growth and cell hydrophobicity, cell surface hydrophobicity could be proposed as the most probable mechanism for hexadecane uptake by the tested yeast strains. Increase in cell hydrophobicity by both yeast strains during growth on hexadecane indicated that the strains could employ biosurfactant-mediated alkane uptake. In fact, Prabhu and Phale suggest that a biosurfactant production and a cell surface hydrophobicity play an important role in hydrocarbon uptake [36]. In this case, the cell contact with hydrophobic compounds is a requirement because the first step in aromatic or aliphatic hydrocarbon degradation is the introduction of molecular oxygen into the molecules by cell-associated oxygenases [37]. Cell hydrophobicity can be considered one of the important factors controlling hydrocarbon assimilation. The yeast strain Trichosporon asahii isolated from petroleum contaminated soil in India by Chandran and Das produced biosurfactant in mineral salt media containing diesel oil as the carbon source and degraded diesel oil (95\%) over a period of 10 days [34]. An extracellular bioemulsifier was isolated from Candida tropicalis and this composed stable hexadecane-inwater emulsions [38].

3.4. Microbial Growth on Hydrocarbon Compounds. The extent of oil-related compounds degradation and the time for complete hydrocarbon compound degradation varied as a function of yeast strains. In addition to their capacity to grow on hexadecane, strains can also grow on some refinery subproduct such as crude oil, diesel fuel, and lubricating oil (Figure 4). Hexadecane was the best substrate to support yeast strains growth. However, the growth of strain belonging to the genus Trichosporon in the presence of diesel fuel showed extended long degradation time (Figure 4(b)). Diesel oil is a medium distillate of petroleum containing $n$-alkanes, branched alkanes, and small concentrations of aromatic polycyclic compounds. Yeast strains were able of utilizing a wide range of hydrocarbons, with a preference for alkanes with intermediate carbon chain lengths. Measurement of growth attributes of the isolates using $n$-hexadecane, diesel oil, and crude oil as substrates showed that the yeast strains were better while using of hydrocarbon substrates. Thus, the biodegradation of mixtures of substrates is an important way in biological treatment of petroleum contaminated wastewater. In fact, petroleum is found typically as complex mixtures in the environment, containing distinct petroleum constituents, such as alkanes (linear, branched, and cyclic), PAHs, heterocyclic aromatic compounds, and asphaltenes. Yeasts are relatively rarely isolated from crude oil or hydrocarbon sources. Moreover, yeasts are capable of using a wide range of different carbon sources [29], though only few studies have been carried out on the potential use of yeast on oil-contaminated sites [39].

The decreased growth pattern in short chain could be attributed to the toxicity of these alkanes to cell membranes [40]. On the other hand, while growth on long chain alkanes could be limited by decreased bioavailability of the substrate, the ability of the yeast isolates to use long chain $n$-alkanes in preference to shorter-chain, ones below $\mathrm{C} 8-\mathrm{C} 10$, could be attributed to reduced toxicity and higher growth yields obtainable from those substrates. Substrates growth could either be due to the constitutive nature of hydrocarbon assimilating capabilities in the isolates or reflect the adaptation of the yeast strains due to previous exposure to exogenous hydrocarbons. It may also indicate the ability of the yeast strains to emulsify hydrocarbons, which is a major factor for hydrocarbon uptake and assimilation.

These results were confirmed also by viable cells enumeration, indicating positive growth with the three substrates shown in Figure 5. These findings suggest that the capacity to degrade crude oil by yeast strains is higher than that by diesel fuel. However, the major compound of diesel fuel is aromatic hydrocarbons. These compounds are more recalcitrant than aliphatic hydrocarbon present in crude oil and lubricating oil [40].

3.5. Degradation of the Alkane and Aromatic Fractions by Yeast Strains. The degradation of the alkane and aromatic hydrocarbons by Candida and Trichosporon species was analyzed by gas chromatography coupled to mass spectrometry (GC/MS). From Figure 6, the strains depicted efficient utilization of the alkane fraction compared to the untreated control. Analysis by GC/MS revealed that both isolates were capable of degrading the aliphatic fractions, which showed that all the detectable hydrocarbons peaks were completely utilized within 12 days by the two yeast isolates. The isolate yeast strains were capable of degrading the entire range of $n$ alkanes on the medium containing petroleum hydrocarbons, from undecane (C11) to hexacosane (C26), as the sole carbon source and energy. The hydrocarbon utilization pattern of yeast strains indicated that the growth was less on short chain alkanes like octane, decane, and undecane. However, 


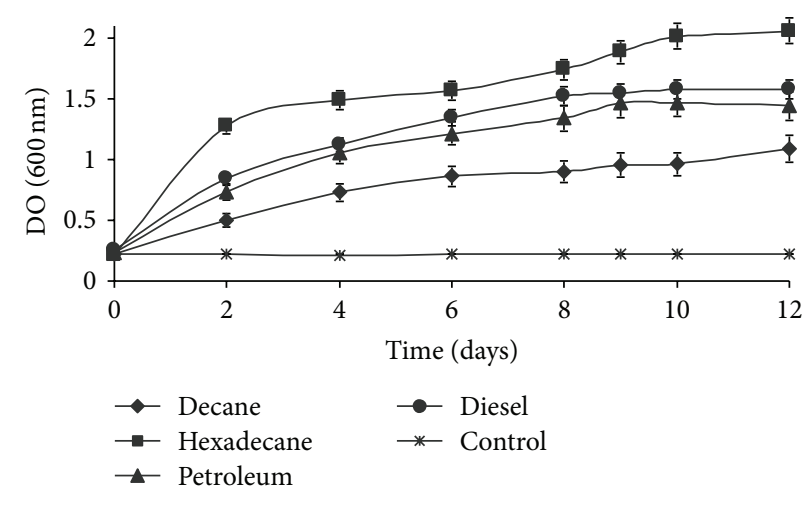

(a) Candida tropicalis

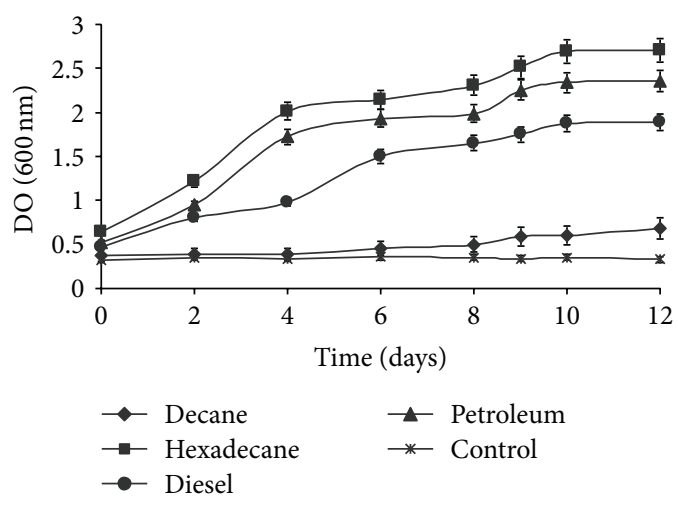

(b) Trichosporon asahii

FIGURE 4: Growth of selected yeasts on mineral medium with some alkanes (1\% w/v) as the sole carbon source with respect to uninoculated controls over 12 days of degradation. (a) Candida tropicalis, (b) Trichosporon asahii.

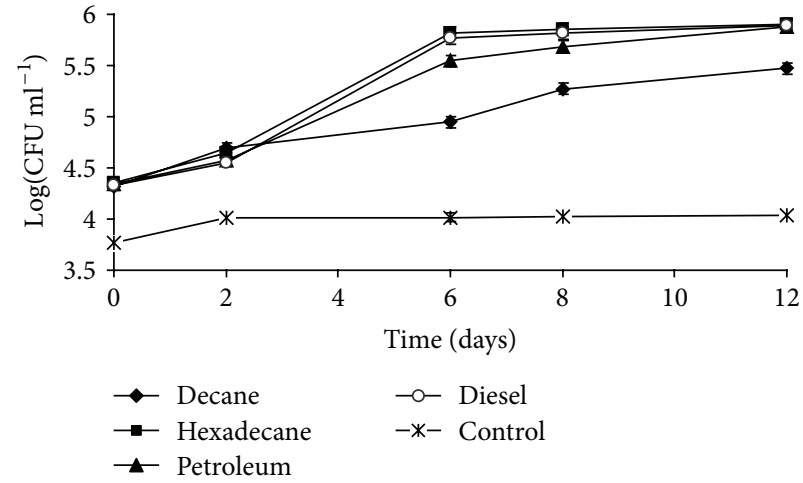

(a) Candida tropicalis

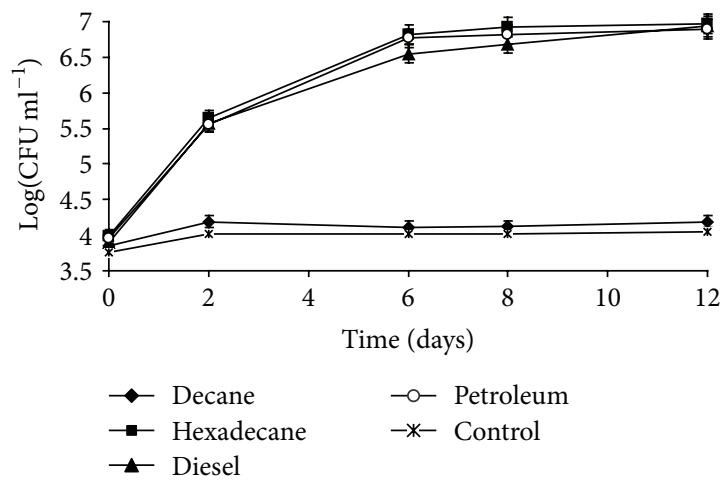

(b) Trichosporon asahii

Figure 5: Yeast cell count during 12 days. (a) Candida tropicalis, (b) Trichosporon asahii. Each point represents mean \pm S.E of triple assays.

it started increasing from dodecane with a maximum growth being observed on heptadecane, octadecane, and nonadecane after which the growth was again comparatively reduced with eicosane, tricosane, tetracosane, and hexacosane (Figure 6). Both short and long chain hydrocarbons of the industrial wastewater refinery were highly susceptible to be attacked by the yeast strains, probably due to the fact that they have a very efficient degradative enzyme system. The strains also showed considerable utilization of components from aromatic fraction as depicted in Figure 7. While Candida and Trichosporon species were capable of efficient degradation of alkanes as the sole carbon source, they were unable to completely degrade aromatic hydrocarbons as the sole carbon source. Aromatic compounds proved to be resistant to biodegradation and we observed that Trichosporon can assimilate phenanthrene, anthracene, and fluoranthene by $47 \%, 73 \%$, and $31.4 \%$, respectively, within 7 days.

The yeast strain Candida species $\mathrm{HCl}$ was capable of degrading a mixture of low and high molecular weight of aromatic hydrocarbons and a degradation efficiency was observed with anthracene (51\%) and fluoranthene (74\%) at the end of 7 days.

Aromatic hydrocarbons are known to be more resistant to biodegradation than aliphatic compounds and are often a serious problem during bioremediation processes $[18,41]$. However, the $n$-alkanes are the most biodegradable petroleum hydrocarbons and are attacked by more microbial species than aromatic or naphthenic compounds. The oxidation of alkanes was considerably more profound than that of aromatic hydrocarbons. This finding is in agreement with other reports where hydrocarbon-degrading microbes have shown preferential degradation of alkanes to aromatics and NSO-asphaltene fractions [18, 42]. However, as expected, the results obtained in the laboratory may not scale up to the natural environment thus we must analyze the behavior of these strains in mesocosm experiments to determine how they may act in the natural environment for the bioremediation of hydrocarbon-polluted wastewater. 

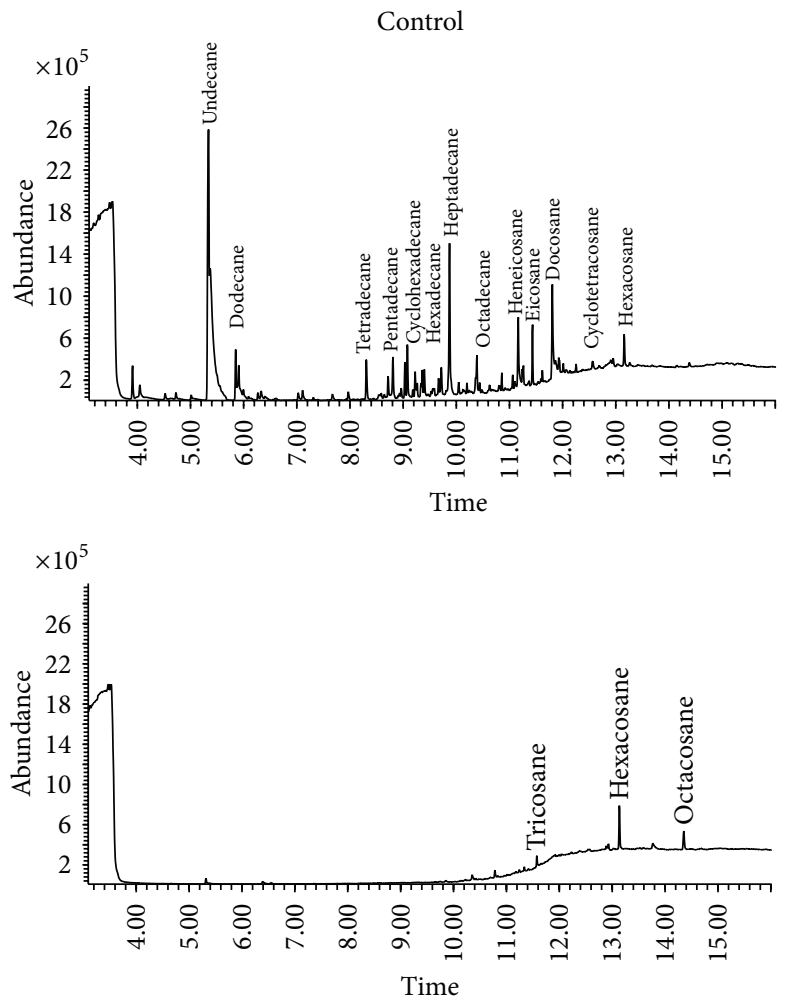

(a) Candida after 12 days of degradation

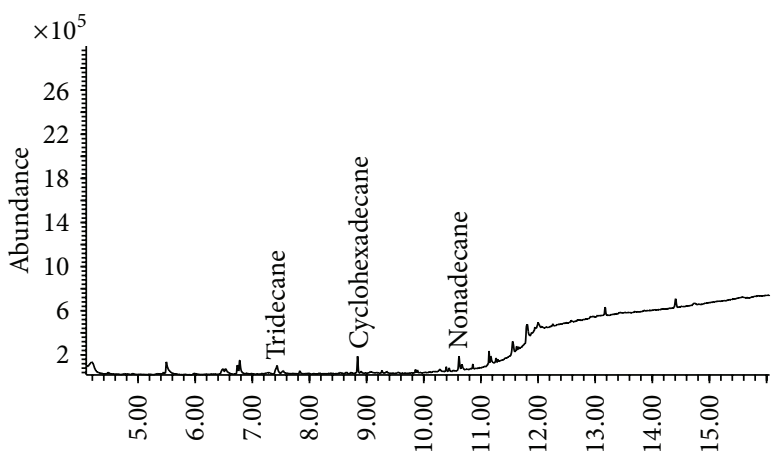

(b) Trichosporon after 12 days of degradation

FIGURE 6: Gas chromatogram showing the biodegradation of alkane fraction of rich-hydrocarbon wastewater from Tunisian refinery by Candida tropicalis (a) and Trichosporon asahii (b) compared to the control.

\section{Conclusion}

Our study focused on the yeast strains isolated from enrichment culture of the contaminated industrial effluent from Tunisian petroleum refinery wastewater, identified as Candida tropicalis and Trichosporon asahii which developed adaptation mechanisms to survive in the harsh environments of that refinery. A direct relationship was found between both cell hydrophobicity of the yeast strains and crude oil biodegradation. These strains have high levels of crude oil degradation and sufficient growth on some aliphatic hydrocarbons. In this study, the isolated yeasts have been shown to degrade a wide range of hydrocarbons and completely metabolize $n$-alkanes. On the other hand, they were unable to completely degrade aromatic hydrocarbons (phenanthrene, anthracene, fluoranthene, and pyrene) as the sole carbon source. From the data presented in this study, it can be concluded that the investigated strains Candida and Trichosporon could be considered as good prospects for their application in bioremediation of hydrocarbon contaminated environment 

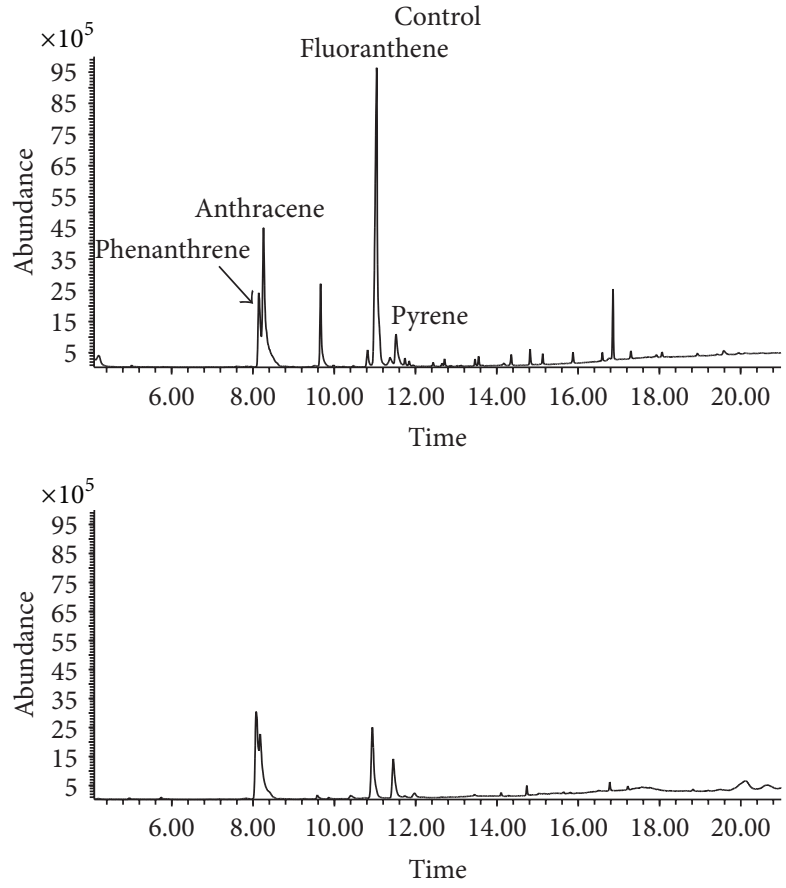

(a) Candida after 7 days of incubation

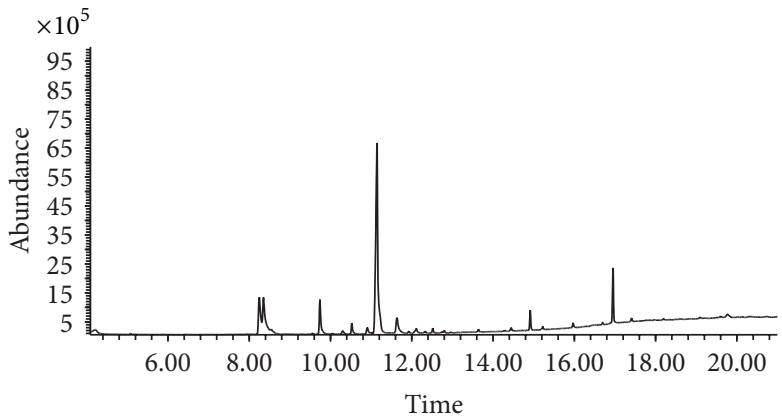

(b) Trichosporon after 7 days of incubation

FIGURE 7: Gas chromatogram showing the biotransformation of the aromatic fraction of rich-hydrocarbon wastewater from Tunisian refinery by Candida tropicalis (a) and Trichosporon asahii (b) compared to the control.

and improvement of hydrocarbon removing treatment of industrial wastewater.

\section{Conflict of Interests}

The authors declare that there is no conflict of interests regarding the publication of this paper.

\section{Acknowledgment}

The authors are grateful to Dr. Mehdi Triki for his priceless helpful comments and for having proofread the manuscript.

\section{References}

[1] M. P. Maila and T. E. Cloete, "The use of biological activities to monitor the removal of fuel contaminants-perspective for monitoring hydrocarbon contamination: a review," International Biodeterioration and Biodegradation, vol. 55, no. 1, pp. 1-8, 2005.

[2] C. J. Berry, S. Story, D. J. Altman et al., "Biological treatment of petroleum in radiologically contaminated soil," in Remediation of Hazardous Waste in the Subsurface. Bridging Flask and Field, C. J. Clark II and A. Stephenson Lindner, Eds., pp. 87-103, American Chemical Society, 2006.

[3] J. D. Van Hamme, A. Singh, and O. P. Ward, "Recent advances in petroleum microbiology," Microbiology and Molecular Biology Reviews, vol. 67, no. 4, pp. 503-549, 2003.

[4] A.-M. Tanase, R. Ionescu, I. Chiciudean, T. Vassu, and I. Stoica, "Characterization of hydrocarbon-degrading bacterial strains isolated from oil-polluted soil," International Biodeterioration \& Biodegradation, vol. 84, pp. 150-154, 2013.

[5] P. O. Okerentugba and O. U. Ezeronye, "Petroleum degrading potentials of single and mixed microbial cultures isolated from 
rivers and refinery effluent in Nigeria," African Journal of Biotechnology, vol. 2, no. 9, pp. 312-319, 2003.

[6] J. F. T. Spencer, A. L. R. de Spencer, and C. Laluce, "Nonconventional yeasts," Applied Microbiology and Biotechnology, vol. 58, no. 2, pp. 147-156, 2002.

[7] M. Hassanshahian, H. Tebyanian, and S. Cappello, "Isolation and characterization of two crude oil-degrading yeast strains, Yarrowia lipolytica PG-20 and PG-32, from the Persian Gulf," Marine Pollution Bulletin, vol. 64, no. 7, pp. 1386-1391, 2012.

[8] N. Sood and B. Lal, "Isolation of a novel yeast strain Candida digboiensis TERI ASN6 capable of degrading petroleum hydrocarbons in acidic conditions," Journal of Environmental Management, vol. 90, no. 5, pp. 1728-1736, 2009.

[9] L.-M. Whang, P.-W. G. Liu, C.-C. Ma, and S.-S. Cheng, "Application of rhamnolipid and surfactin for enhanced diesel biodegradation-effects of $\mathrm{pH}$ and ammonium addition," Journal of Hazardous Materials, vol. 164, no. 2-3, pp. 1045-1050, 2009.

[10] S. Mnif, M. Chamkha, and S. Sayadi, "Isolation and characterization of Halomonas sp. strain C2SS100, a hydrocarbondegrading bacterium under hypersaline conditions," Journal of Applied Microbiology, vol. 107, no. 3, pp. 785-794, 2009.

[11] M. O. Ilori, S. A. Adebusoye, and A. C. Ojo, "Isolation and characterization of hydrocarbon-degrading and biosurfactantproducing yeast strains obtained from a polluted lagoon water," World Journal of Microbiology and Biotechnology, vol. 24, no. 11, pp. 2539-2545, 2008.

[12] S. Chakraborty and S. Mukherji, "Surface hydrophobicity of petroleum hydrocarbon degrading Burkholderia strains and their interactions with NAPLs and surfaces," Colloids and Surfaces B: Biointerfaces, vol. 78, no. 1, pp. 101-108, 2010.

[13] S. Zinjarde, M. Apte, P. Mohite, and A. R. Kumar, "Yarrowia lipolytica and pollutants: interactions and applications," Biotechnology Advances, vol. 32, pp. 920-933, 2014.

[14] B. Gargouri, F. Karray, N. Mhiri, F. Aloui, and S. Sayadi, "Application of a continuously stirred tank bioreactor (CSTR) for bioremediation of hydrocarbon-rich industrial wastewater effluents," Journal of Hazardous Materials, vol. 189, no. 1-2, pp. 427-434, 2011.

[15] Bergey's Manual of Determinative Bacteriology, vol. 87, Williams and Wilkins, Baltimore, Md, USA, 9th edition, 1994.

[16] S. Abdelkafi, S. Sayadi, Z. B. Ali Gam, L. Casalot, and M. Labat, "Bioconversion of ferulic acid to vanillic acid by Halomonas elongata isolated from table-olive fermentation," FEMS Microbiology Letters, vol. 262, no. 1, pp. 115-120, 2006.

[17] M. Rosenberg, D. Gutnick, and E. Rosenberg, "Adherence of bacteria to hydrocarbons: a simple method for measuring cellsurface hydrophobicity," FEMS Microbiology Letters, vol. 9, no. 1, pp. 29-33, 1980.

[18] S. Mishra, J. Jyot, R. C. Kuhad, and B. Lal, "In situ bioremediation potential of an oily sludge-degrading bacterial consortium," Current Microbiology, vol. 43, no. 5, pp. 328-335, 2001.

[19] I. Masneuf-Pomarède, C. Le Jeune, P. Durrens, M. Lollier, M. Aigle, and D. Dubourdieu, "Molecular typing of wine yeast strains Saccharomyces bayanus var. uvarum using microsatellite markers," Systematic and Applied Microbiology, vol. 30, no. 1, pp. 75-82, 2007.

[20] T. J. White, T. Bruns, S. Lee, and J. Taylor, "Amplification and direct sequencing of fungi ribosomal RNA genes for phylogenetics," in PCR Protocols. A Guide to Methods and Applications, M. A. Innis, D. H. Gelfand, J. J. Sninsky, and T.
J. White, Eds., pp. 315-322, Academic Press, San Diego, Calif, USA, 1990.

[21] K. O'Donnell, "Fusarium and its near relatives," in The Fungal Holomorph: Mitotic, Meiotic and Pleomorphic Speciation in Fungal Systematics, D. R. Reynolds and J. W. Taylor, Eds., pp. 225-233, CAB International, Wallingford, UK, 1993.

[22] S. F. Altschul, T. L. Madden, A. A. Schäffer et al., "Gapped BLAST and PSI-BLAST: a new generation of protein database search programs," Nucleic Acids Research, vol. 25, no. 17, pp. 3389-3402, 1997.

[23] R. C. Edgar, "MUSCLE: multiple sequence alignment with high accuracy and high throughput," Nucleic Acids Research, vol. 32, no. 5, pp. 1792-1797, 2004.

[24] N. Saitou and M. Nei, "The neighbor-joining method: a new method for reconstructing phylogenetic trees," Molecular Biology and Evolution, vol. 4, no. 4, pp. 406-425, 1987.

[25] K. Tamura, J. Dudley, M. Nei, and S. Kumar, "MEGA4: Molecular Evolutionary Genetics Analysis (MEGA) software version 4.0," Molecular Biology and Evolution, vol. 24, no. 8, pp. 15961599, 2007.

[26] S. Cappello, R. Denaro, M. Genovese, L. Giuliano, and M. M. Yakimov, "Predominant growth of Alcanivorax during experiments on 'oil spill bioremediation' in mesocosms," Microbiological Research, vol. 162, no. 2, pp. 185-190, 2007.

[27] R. Margesin, C. Moertelmaier, and J. Mair, "Low-temperature biodegradation of petroleum hydrocarbons ( $n$-alkanes, phenol, anthracene, pyrene) by four actinobacterial strains," International Biodeterioration and Biodegradation, vol. 84, pp. 185-191, 2013.

[28] K. S. M. Rahman, I. M. Banat, J. Thahira-Rahman, and P. Lakshmanaperumalsamy, "Towards efficient crude oil degradation by a mixed bacterial consortium," Bioresource Technology, vol. 85, no. 3, pp. 257-261, 2002.

[29] C. Schmitz, I. Goebel, S. Wagner, A. Vomberg, and U. Klinner, "Competition between $n$-alkane-assimilating yeasts and bacteria during colonization of sandy soil microcosms," Applied Microbiology and Biotechnology, vol. 54, no. 1, pp. 126-132, 2000.

[30] A. E.-L. Hesham, S. A. Alamri, S. Khan, M. E. Mahmoud, and H. M. Mahmoud, "Isolation and molecular genetic characterization of a yeast strain able to degrade petroleum polycyclic aromatic hydrocarbons," African Journal of Biotechnology, vol. 8, no. 10, pp. 2218-2223, 2009.

[31] C. P. Kurtzman, C. J. Robnett, and D. Yarrow, "Two new anamorphic yeasts: Candida germanica and Candida neerlandica," Antonie van Leeuwenhoek, vol. 80, no. 1, pp. 77-83, 2001.

[32] S.-O. Suh, N. H. Nguyen, and M. Blackwell, "Yeasts isolated from plant-associated beetles and other insects: seven novel Candida species near Candida albicans," FEMS Yeast Research, vol. 8, no. 1, pp. 88-102, 2008.

[33] G. Scorzetti, J. W. Fell, A. Fonseca, and A. Statzell-Tallman, "Systematics of basidiomycetous yeasts: a comparison of large subunit D1/D2 and internal transcribed spacer rDNA regions," FEMS Yeast Research, vol. 2, no. 4, pp. 495-517, 2002.

[34] P. Chandran and N. Das, "Biosurfactant production and diesel oil degradation by yeast species Trichosporon asahii isolated from petroleum hydrocarbon contaminated soil," International Journal of Engineering Science and Technology, vol. 2, pp. 69426953, 2010.

[35] P. Chandran and N. Das, "Degradation of diesel oil by immobilized Candida tropicalis and biofilm formed on gravels," Biodegradation, vol. 22, no. 6, pp. 1181-1189, 2011. 
[36] Y. Prabhu and P. S. Phale, "Biodegradation of phenanthrene by Pseudomonas sp. strain PP2: novel metabolic pathway, role of biosurfactant and cell surface hydrophobicity in hydrocarbon assimilation," Applied Microbiology and Biotechnology, vol. 61, no. 4, pp. 342-351, 2003.

[37] C. D. Coimbra, R. D. Rufino, J. M. Luna, and L. A. Sarubbo, "Studies of the cell surface properties of candida species and relation to the production of biosurfactants for environmental applications," Current Microbiology, vol. 58, no. 3, pp. 245-251, 2009.

[38] C. D. Coimbra, R. D. Rufino, J. M. Luna, and L. A. Sarubbo, "Studies of the cell surface properties of Candida species and relation to the production of biosurfactants for environmental applications," Current Microbiology, vol. 58, no. 3, pp. 245-251, 2009.

[39] M. Yang and S. Zheng, "Pollutant removal-oriented yeast biomass production from high-organic-strength industrial wastewater: a review," Biomass and Bioenergy, vol. 64, pp. 356362, 2014.

[40] G. C. Okpokwasili and S. C. Amanchukwu, "Petroleum hydrocarbon degradation by Candida species," Environment International, vol. 14, no. 3, pp. 243-247, 1988.

[41] P. Wongsa, M. Tanaka, A. Ueno, M. Hasanuzzaman, I. Yumoto, and H. Okuyama, "Isolation and characterization of novel strains of Pseudomonas aeruginosa and Serratia marcescens possessing high efficiency to degrade gasoline, kerosene, diesel oil, and lubricating oil," Current Microbiology, vol. 49, no. 6, pp. 415-422, 2004.

[42] B. Gargouri, F. Aloui, and S. Sayadi, "Reduction of petroleum hydrocarbons content from an engine oil refinery wastewater using a continuous stirred tank reactor monitored by spectrometry tools," Journal of Chemical Technology and Biotechnology, vol. 87, no. 2, pp. 238-243, 2012. 

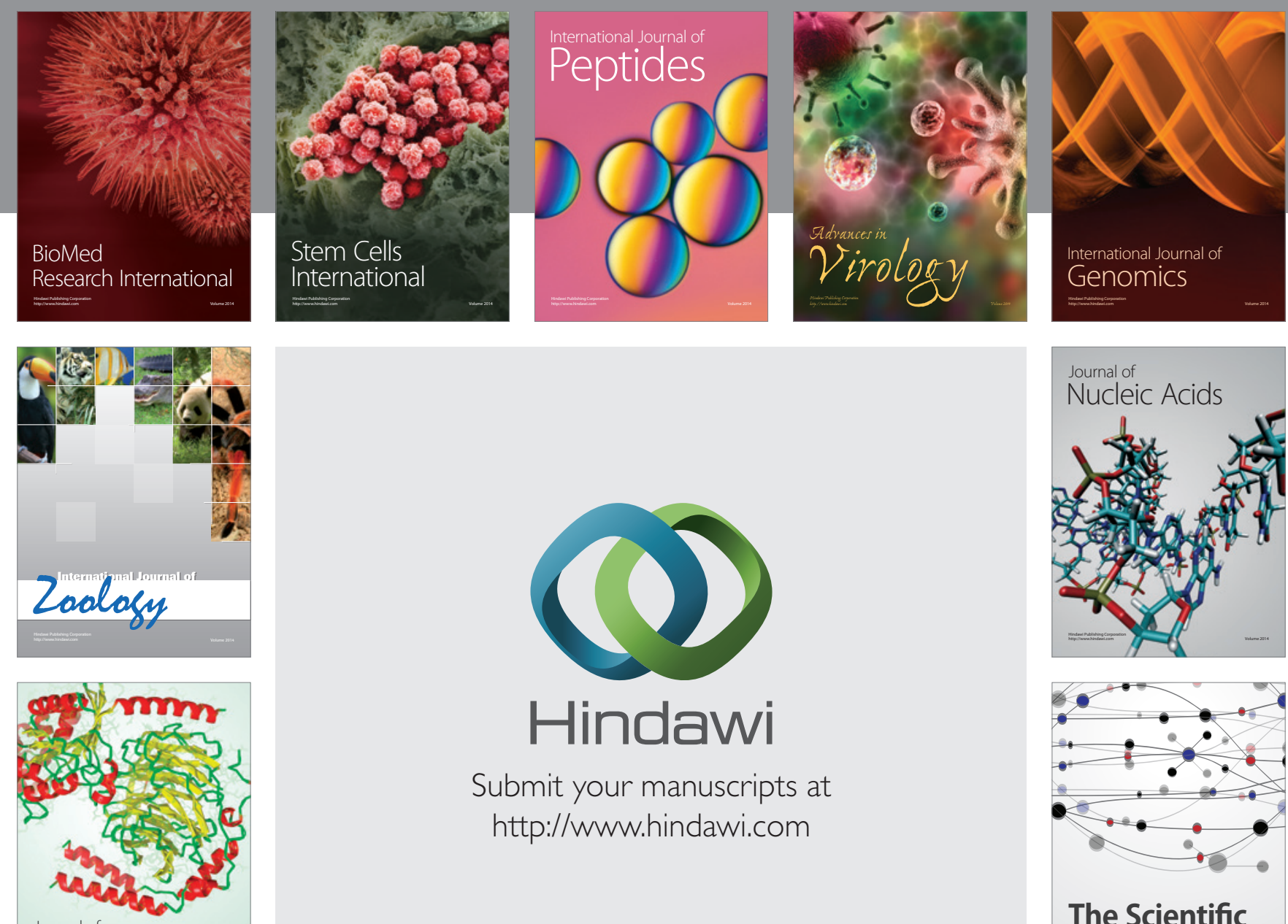

Submit your manuscripts at

http://www.hindawi.com

Journal of
Signal Transduction
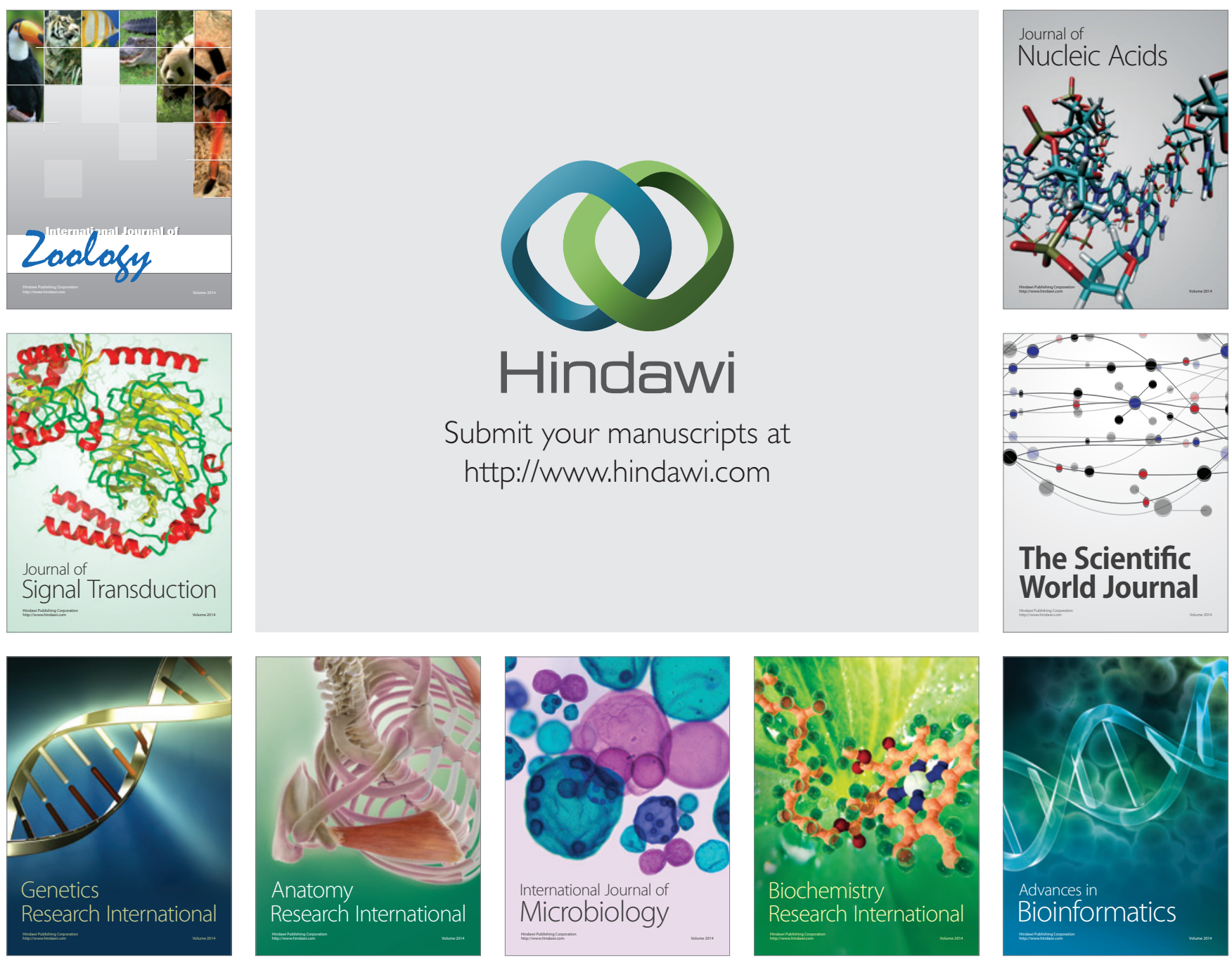

The Scientific World Journal
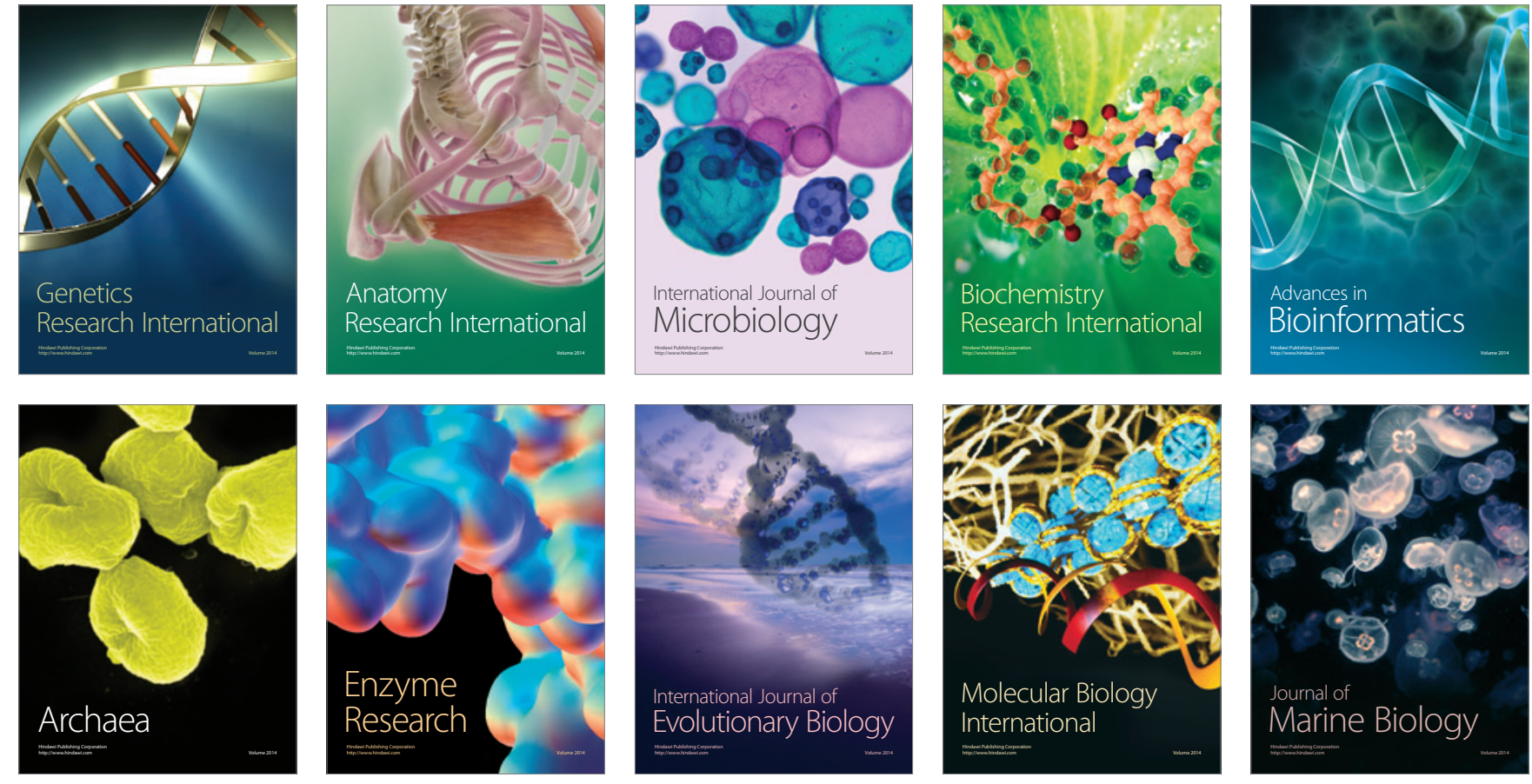